\title{
Update on Human Bone Hydatid Disease
}

\author{
Mulambalah Chrispinus Siteti ${ }^{1,}$,, Siteti Darwin Injete ${ }^{2}$ \\ ${ }^{1}$ Department of Medical Microbiology \& Parasitology, School of Medicine, College of Health Sciences, Moi University, Eldoret, Kenya \\ ${ }^{2}$ College of Health Sciences, Jomo Kenyatta University of Agriculture and Technology, Nairobi, Kenya
}

\author{
Email address: \\ csmulambalah@gmail.com (M. C. Siteti), darwinsiteti@gmail.com (S. D. Injete)
}

\section{To cite this article:}

Mulambalah Chrispinus Siteti, Siteti Darwin Injete. Update on Human Bone Hydatid Disease. Science Journal of Clinical Medicine.

Vol. 4, No. 1, 2015, pp. 10-17. doi: 10.11648/j.sjcm.20150401.13

\begin{abstract}
Hydatid disease is public health problem worldwide causing considerable health and economic loss. The disease may develop in almost any part of the human body. Bone involvement is often asymptomatic and diagnosis is primarily based on radiographic findings. Bone hydatidosis is less frequent than primary hydatidosis of the visceral organs. The localization of hydatid cysts in the bones has been little studied and so there is inadequate information in literature on the subsequent disease evolution from primary hydatidosis. We present a detailed review on hydatidosis of the bony skeleton particularly of patients who normally seek medical attention late. The review underlines the difficulties of diagnosis and treatment of bone hydatid disease and its variants that may be currently under-/mis-diagnosed in disease endemic areas. We hope to stimulate a high index of suspicion among clinicians to facilitate early diagnosis and to consider the disease(s) as a differential diagnosis in cases of multiple abnormal activities in bones especially among middle aged and elderly people in endemic areas. Bone hydatid disease treatment and management is delicate, expensive and risky and in most cases reccur at some point. We therefore advocate for improved active methods of disease prevention in endemic areas.
\end{abstract}

Keywords: Hydatidosis, Osseous Disease, Differential Diagnosis, Surgical Treatment, Antihelminthics

\section{Introduction}

Echinococcosis (hydatid disease or hydatidosis) is an infectious disease caused by the larval (metacestode) stages of cestodes belonging to the genus Echinococcus in the family Taeniidae. The genus has four species of medical importance associated with various forms of echinococcosis. These are: Echinococcus granulosus causes cystic echinococcosis, E.multilocularis causes alveolar echinococcosis, E.vogeli causes polycystic echinococcosis and E.oligathrus is an extremely rare cause of human echinococcosis. Infection occur either through direct ingestion of parasite eggs from contact with infected dogs [definitive hosts] or indirectly from the ingestion of contaminated water or food. Once ingested, the eggs hatch to release larval ochospheres that penetrate intestinal wall to reach various tissues of intermediate hosts via general blood circulation. In the tissues the onchospheres transform into proliferative hydatid cysts. Man is considered an accidental intermediate host in which the larval cysts locate mainly in the liver and lungs causing primary hydatid disease. Infestation of hydatid disease in humans most commonly occurs in the liver (55-70\%), followed by the lungs (18-35\%). Bone hydatidosis however is very rare [1].
The most common species are Echinococcus granulosus and Echinococcus multilocularis whose geographic distributions differ markedly, with E. multilocularis being restricted to temperate regions of North America, Europe, and Asia [2]. Echinococcus granulosus has a worldwide geographic distribution and occurs in all continents including circumpolar, temperate, subtropical and tropical zones [3]. The highest prevalence of the parasite is found in parts of Eurasia, Africa, Australia and South America [4]. In subSaharan Africa, especially in East and West Africa, cystic hydatid disease is highly endemic [5]. Within endemic zones, the prevalence of the parasite varies from sporadic to high, but only a few countries can be regarded as being free of $E$. granulosus. The highest prevalence rates have been reported in some pastoralist communities in Kenya [6]. However, with an increase in foreign travel and migration of people, there is likelihood of infection being transferred to other parts of the world. Therefore there is need for practitioners to be aware of disease and its rarer manifestations. This is because cystic hydatidosis is responsible for the largest series of surgical hydatid patients from Africa and demonstrates the wide diversity in cyst location in the human body. Most of the operations have ended up tragically. In 2010, it caused about 
1200 deaths down from 2000 in 1990 [7]. The economic cost of the disease is estimated to be around 3 billion USD a year [8]. Hydatid disease is therefore one of the neglected chronic diseases with serious impact on health and economy especially in countries where it is endemic.

Bone hydatid disease also known as osseous disease is a rare entity accounting for $0.5 \%$ to $4 \%$ of all human hydatidosis cases $[9,10]$. The diagnosis of osseous hydatidosis is primarily based on radiological findings. Treatment is difficult and recurrence is common [11]. In this regard, plain radiography, CT scan, and MR imaging are helpful in diagnosing skeletal cystic echinococcosis [12]. Osseous foci may manifest as bone pain and deformity, particularly among patients in the 30-60 year old age group [13].

Bone hydatid disease as a rare disease has received inadequate research attention and yet case reports are increasingly cited in medical literature. The aspects on the cysts localization in the bony skeleton have been inadequately studied and so there is little information in literature on the subsequent disease evolution, diagnosis, treatment and management.

\section{Osseous Hydatid Disease}

Hydatid disease generally affects lungs and liver however, bone, muscle, peritoneum, heart, kidney, and brain involvement has been reported [14] even though the incidence of musculoskeletal involvement is low and considered rare [15]. Skeletal involvement usually occurs by the dissemination of hydatid cysts from the primary disease from the liver and lungs. Cases of vertebra, femur, tibia, and pelvic involvement have been previously reported [16]. Skeletal involvement often presents with sciatica, hip and groin pain. A case of hydatid disease with sacroiliac joint involvement mimicking ankylosing spondylitis (AS) has been reported. Differential diagnosis is mostly confirmed with imaging techniques.

Osseous hydatid disease is defined as development within bone of multiple cysts that are the larval forms of the tapeworm [17]. Incidence of hydatid disease of bone from various studies is reported to be $0.5-4 \%$. [18]. Disease incidence is extremely low because most the larvae are trapped by the liver and lung upon release of the embryo into the portal blood stream. Skeletal hydatidosis results from the deposition of the larval forms filtered out of liver/lungs into the bone tissue. The diagnostic interpretation of imaging studies in skeletal disease prove very confusing because bone changes evolve with time, and the non-specificity of these findings often leads to a mistaken and or missed diagnosis [16].

The behavior of osseous hydatid cysts resembles that of local malignant lesions. This illustrates that in the absence of a high index of suspicion for echinococcal infection, the semblance of imaging findings of hydatid disease in bone to those of other skeletal pathologies can lead to misinterpretation, misdiagnosis and therefore wrong treatment.

Primary isolated bone hydatid disease is a very rare occurance but commonly characterized by bone lesions. The lesions in bone may lie dormant for 10 to 20 years [19] and later present with pain or pathological fractures following trivial injuries. No other skeletal disease is more difficult to diagnose, treat and or eradicate as bone echinococcosis. This is due to lack of connective tissue barriers in the bone which allows progressively enlarging daughter cysts extend to fill the medullary cavity to a variable extent replacing the medulla [16]. The treatment rests on surgical excision but cases of recurrence are common particularly at sites that are difficult to access [17].

Unique cases of simultaneous cardiac and spinal involvement are uncommon but separately constitute $0.3-1 \%$ of all hydatid cases. In such cases, patients present with multiple and severe complications [20] and may require several operations to remove cysts with high possibility of relapses and disease spread to other organs.

Even though hydatid cyst occurrence in the bones is rare, information on the distribution and localization of disease in the bony skeleton can help improve knowledge on diagnosis, treatment, control and prevention [21]. Approximately 60\% cases of bone hydatidosis affect the spine and pelvis, $28 \%$ the long bone and $8 \%$ the ribs and scapula [22] and based on this, two main variants of the bone hydatid disease are reported in literature as spinal hydatid disease (affecting the spine) and extraspinal hydatid disease (affecting any other parts of the bony skeleton apart from the spine). For both cases treatment rests on surgical excision and recurrence is a common occurance.

\subsection{Spinal Hydatid Disease}

In bone hydatid disease, the spine is the common site of infection [9]. Hydatid disease of spine usually spreads over the spine by direct extension from pulmonary, abdominal or pelvic infestation and most commonly affects the thoracic vertebrae (52\%), followed by the lumbar (37\%) and then the cervical and sacral spine [23]. The disease is usually silent until a complication for instance paraplegia or pathologic fracture occurs. Many cases are diagnosed intraoperatively [17].

An increasing number of elderly patients [with a mean age of 53.1 years] of both genders with spinal hydatidosis seeking treatment are reported in literature. The areas of spine commonly affected are the cervical spine, the dorsal spine, the lumbar spine and the sacrum [24]. Majority of them exhibit spinal injury and neurological damage that require urgent surgical intervention. Disease recurrence after surgery in such patients is frequent.

The vertebral column is frequently affected in $0.2-1 \%$ of all patients of which spine is involved in approximately $45 \%$ of cases $[15,25,26,27]$. Due to the rarity of its presentation, unless the clinician includes spinal hydatid disease as part of the differential diagnostic list for paralysis and considers performing neuroimaging, this potentially curable disease can be missed [28, 29, 30, 31].

Vertebral hydatidosis in most reported cases involves the 
thoracic vertebrae and the cervical, lumbar vertebrae and sacrum are rare sites [32, 33, 34, 35, 36]. However, it remains controversial as to which region of the spine is more commonly involved [37]. The controversy should be addressed through further research work.

Spinal hydatid disease manifests itself through a variety of symptoms and signs related to compression of the cysts on other structures and no specific pathognomonic symptoms or signs exist [38, 39]. It may present with radiculopathy, myelopathy and/or local pain owing to bony destructive lesions, pathological fracture and consequent cord compression $[15,40]$. In some patients, the spinal hydatid cysts can grow to enormous size and clinically remain asymptomatic for years [15, 40, 41,]. Hydatid cysts of the sacrum are no exception and are characterized by chronicity without any clinical manifestation and usually misdiagnosed in the early stages, resulting in significant loss of bone and destruction of surrounding tissue [42].

A missed diagnosis of bone hydatid cyst could be devastating and hydatid cyst should be kept as a differential diagnosis when encountered with a cystic lesion of sacrum and vertebral column involvement [35] in this regard, a multidisciplinary approach would be appropriate for diagnosing and monitoring of suspected hydatid lesions [43]. Even patients with suspected abdominal or lung echinococcosis should also be investigated for other localizations such as the brain, spine and heart. Furthermore, in endemic areas hydatidosis must be suspected in the presence of lesions occupying space in these organs.

Localization of cysts in spinal hydatidosis with variable presentations referred to in literature as 'unusual cases' have been reported. Reports of patients presenting at medical facilities with spinal disease indicate that bone lesions associated with hydatid cysts at other parts of the spine are increasing in endemic areas. These include the cervical intramedullar of cervical vertebrae [44], upper cervical spine (craniocervical junction) [45] and lateral cervical region of head and neck [46] in most cases associated with cord compression and neurological disorders. Pathologically confirmed multiple distinct spinal intradural extramedullar spinal hydatid cysts during operations also reported [47].

Some of the unusual presentations of recurrent hydatid disease may be linked to spillage of hydatid cysts from symptomatic primary spinal hydatid disease [48]. The recurrence period of spinal hydatid disease may be silent without any neurologic deficits or pain; the only clinical manifestation may be leakage from a cyst. In such cases curative therapies remain unlikely, but periodic follow-up MR images are advisable for early diagnosis of recurrence in order to obtain effective treatment.

Certain cases of spinal hydatid disease mimick other bone diseases for instance tuberculosis spondylodiscitis (Pott's disease) [49] and may be misdiagnosed as tuberculosis [50]. It is therefore suggested that spinal hydatid disease should be considered in the differential diagnosis of spondylodiscitis in endemic countries, and tested for with imaging and serology.

Spinal hydatid disease is a progressive disease that is associated with risks of serious morbidity [51] and secondary infections. Reports of secondary infections accompanying this disease have been published. Therefore clinicians should bear in mind that spinal hydatidosis may be accompanied by other infections in endemic regions. Co-infection with other infectious diseases has been rare but cases are emerging in literatute with regard to human immunodefiency virus (HIV) infection [52]. Although infrequent, infections by cestodes constitute a cause of disease in HIV-infected patients, especially in endemic areas. This is probably an indication that primary spinal cyst hydatid could in future be an added complication in patients with acquired immunodeficiency syndrome and other disease conditions in endemic areas.

The treatment of choice in spinal hydatid disease is surgery [53], but surgery alone is not curative. Adjuvant drug therapy as well as intraoperative prophylaxis is recommended. Despite all treatment measures, the disease has high recurrence rates and overall outcome is still poor in majority of cases.

\subsection{Extraspinal Bone Hydatid Disease}

Extraspinal locations are even rarer than spinal hydatidosis but cases are emerging involving other bony parts of the skeleton in what is known as extraspinal osseous hydatidosis. The infected areas are ilium in sacral ala, the hip, the femoral head and the acetabular roof, the femoral shaft, the distal part of the femur, the femoral, the scapula and the ribs [54, 55].

A few exceptional cases of hydatid cyst localization in ribs have been reported in retrospective studies [56]. The clinical picture was characterized by chest pain and by swelling with general health described as satisfactory in all patients. Hydatid disease of the ribs is a very rare disorder and the diagnosis is difficult and it is sometimes an unexpected encounter [57]. Primary hydatid cyst of the rib in childhood is even exceedingly rare but when encountered, pediatric hydatid cyst of the rib mimick chest wall tumor(s).

Pelvic hydatid disease has been reported involving bilateral hydatid cyst of the pelvis presented with adnexal cystic mass [58]. Several cases of hydatidosis of pelvis and femur are emerging in literature particularly in the elderly. Patients often present with swelling and deformity of upper and middle third of thigh. Extensive hydatidosis of the femur with pathological fracture and involvement of the pelvis bone, without involvement of abdominal viscera widely reported $[59,60]$. In disease endemic North Africa, exceptional cases of primary pelvic hydatid cyst have been diagnosed and reported in elderly people [61]. It is suggested that any hypoechogenic pelvic lesion in a patients originating from countries in the region should be considered as a possible pelvic localization of Echinococcus granulosus.

Analysis of long term follow-up study findings suggest that cerebral hydatid cysts account for up to $3.6 \%$ of all intracranial space-occupying lesions, in endemic countries. The vast majority of patients affected are children [62]. This is interesting because, other cases of bone hydatid disease involve the elderly (mean age 54 years.).

In endemic areas, 3-4\% of skeletal hydatid cysts are found in the skull [63]. Cases of primary hydatidosis involving the 
cranial vault are revealed by a bulging mass of the forehead and symptoms of raised intracranial pressure reported in patients seeking medical attention. It is suggested that hydatid cyst should be considered in the differential diagnosis of any soft tissue swelling or osteolytic lesion in the scalp of patients living in endemic areas.

Osseous cysts of foot infestation have been reported as a palpable mass at the medial dorsal aspect of the midfoot [64] and may present as infective or neoplastic pathology. A high index of suspicion is necessary for its diagnosis, especially in patients who live in or travel to areas where hydatid disease is endemic.

Radiological and histopathological reports indicate isolated cases of hydatid cyst in the lower third of radius that required wide excision and post-operative albendazole [65] and a case of hydatidosis of the hip and pelvis characterized by severe pain and swelling of thigh [66]. These cases are difficult to treat and usually require repeated excisions and long follow up periods to confirm complete healing.

Depending on the location, some bone cysts cannot be easily detected by available advanced imaging and laboratory investigation modalities. Such cases include primary hydatid cyst in the scaphoid [67] and cysts located in extra- and intracranial spaces [68]. Images from these sites lack enhanced contrast thus difficult to interprate and confirm diagnosis. The few reported cases were encountered as intraoperative clinical suspicions.

Primary hydatid bone disease, where there is no evidence of systemic disease, is more unusual and tibia involvement occurs in up to $15 \%$ of such cases [10]. Patients present with infapatellar pain and walking disability due to cystic lesion which involve metaphysis and diaphysis of proximal tibia. These lesions clinically manifest when patients suffer any type of complications. A related case of primary hydatid cyst of the tibia presenting with a pathologic fracture simulating benign bone cystic lesion is reported [69]. In both cases the lesions were usually osteolytic and involved cortical bone and extended to soft tissues. These cases emphasize the importance of considering hydatid disease in the differential diagnosis of cystic bone lesions, especially in individuals coming from regions where the disease is endemic.

Involvement of the long tubular bones is rare in hydatid bone disease. Patients are initially asymptomatic and usually present at a later stage of the disease when the bony lesions are extensive [70]. Diagnosing long bone hydatid disease (diaphyseal hydatid disease) is challenging, even in endemic regions, and a high index of suspicion is required because the radiologic findings often mimic other bone pathologies. For instance diaphyseal bone hydatidosis can be initially misdiagnosed as a low-grade malignant tumor and given wrong treatment. Recurrence following treatment can occur after a long period of quiescence.

\section{Diagnosis}

The most common radiological manifestation of skeletal hydatid disease is a lucent expansile lesion with cortical thinning. Bone hydatid disease lacks a typical clinical appearance and image characteristics on X-ray or computed tomography (CT) scan are similar to those of tuberculosis, metastases, giant cell tumour or bone cysts [71]. The primary role of $\mathrm{CT}$ in diagnosis is in the recognition of the extraosseous spread of the hydatid disease within the soft tissues which is quite variable and may have the typical pattern of a cystic lesion seen as a round or oval area containing fluid, with sharp and thin margins, exhibiting no contrast enhancement.

Magnetic resonance imaging (MRI) shows distinctive diagnostic features of bone hydatid disease, especially in the spine bones. The magnetic resonance imaging signal intensity pattern of the hydatid daughter cysts reflect their contents and may vary depending on whether cysts are dead or alive.

Radiologically, computed tomography (CT) scanning and ultrasonography remain a useful combination recommended for both achieving a correct diagnosis and for planning of appropriate treatment $[25,72]$. The diagnosis of cystic lesions in the sacrum requires experience and necessary skills to achieve differential diagnosis of different cystic lesions [32].

Magnetic resonance imaging (MRI) is the preferred imaging tool in the diagnosis of hydatid cysts located in various parts of body and recent use of diffusion-weighted [DwMRI] is reported to help differentiate complicated infected hydatidosis from abscesses, epidermoid cysts from arachnoid cysts, and benign from malignant vertebral compression fractures [27, 74]. Diffusion-weighted MRI can also help differentiate between infections requiring immediate surgery and those that can be treated medically with antihelmintic treatment [74]. Fine needle aspiration cytology used in the diagnosis of hydatid cyst without procedure-related complication is reported in literature but is not recommended due to risk of spillage and consequent systemic spread of hydatid cyst.

\section{Treatment}

The only definitive treatment of bone hydatid disease is complete resection of the involved area with a wide healthy margin. The combination of antihelminthic therapy, wide resection and the use of polymethylmethacrylate (PMMA) results in the best outcome in the treatment of bone hydatidosis. However, successful treatment of spinal hydatid disease necessitates careful neuroradiological evaluation, aggressive surgical intervention and this plus adjuvant chemotherapy in some cases. This mode of treatment is widely accepted and used $[25,75,76]$.

The initial treatment of choice should be surgical excision for neural decompression, and establishing diagnosis and en masse excision of the spinal lesion depends largely on the location and the extent of the lesion [33]. Various parameters have to be considered before undertaking an operation. These include the type of surgical procedures, extent of resection and decision whether to perform spinal stabilization or not, the site and extent of the disease and bone involvement and the nature of destruction causing spinal instability [39, 77]. 
Antiheminthics are commonly used agents in treatment of primary and secondary hydatid disease. Albendazole is the preferred antihelminthic agent used before and after surgery to reduce risk of recurrence and/or facilitate surgery by reducing intracystic pressure $[37,76]$. However, there is reported controversy on the duration of treatment [76] that necessitates further research inquiry. The widely accepted mode of use of albendazole has been for hydatid cyst aspiration and reperfusion [15, 32, 33].

Follow-up periods of variable duration are critical intergral aspect in the management of bone hydatid disease patients. Follow ups are important in identification of postoperative complications, in confirmation of cure and recurrent cases $[25,26,79]$. During follow-ups, regular MRI scans should be done to ensure that any recurrence cases are detected early and and patients advised accordingly [79].

Even after best optimal treatment of bone hydatid disease, recurrent cases are envitable. Such cases require reoperations and are widely reported in literature $[80,81]$. The recurrence rate of bone hydatid disease is approximated at $30-40 \%$ but the rate could be higher if longer follow-ups are undertaken in future studies [82] particularly for those who live or travel regularly within endemic areas. For this reason, it is recommended that spinal hydatidosis should be considered in the differential diagnosis of any patient who has been previously treated for the disease, lived or traveled within endemic areas and who presents with spine lesions and cord compression [83].

\section{Conclusion}

Skeletal cystic lesions are rare yet because of their unusual presentation, diagnosis can be missed. Surgeons should be alert to bone hydatid disease, the disease should be suspected in cystic lesions affecting any organ of the body and in pathological fractures especially in endemic areas of the world.

Early diagnosis helps in appropriate treatment and salvage of the bone whereas misdiagnosis and delayed diagnosis are always fraught with the danger of amputation, recurrence and sepsis. The diagnosis should include confirmed clinicoradiologically assessment before treatment with chemotherapy and or considered for surgery. Many patients die after surgery and some may require long periods of follow up which in many cases is costly and unsustainable in poor developing countries.

The radiological appearance of the hydatid disease of musculoskeletal system mimick tumors, and other inflammatory bone conditions and creates diagnostic challenges. Therefore preoperative diagnosis of musculoskeletal hydatid disease may sometimes difficult clinically and radiologically. On radiography, different radiographic changes may occur in the bone as the disease evolves. In cases of osteolytic and inflammatory changes, it may mimic any variant of nonspecific or specific osteomyelitis. Bone erosion and destruction may lead to almost complete osteolysis, bone may distort, and its radiologic appearances may be confused with those of a malignant bone tumor.

Computed tomography (CT) is more accurate in delineating the area of bone destruction in bone hydatid disease. The technique together with magnetic resonance imaging is used in the recognition of extraosseous spread of the hydatid disease within the soft tissues and bones.

The treatment of choice of spinal hydatidosis is surgical removal of hydatid cyst(s) without rupture from the affected area of the bone combined with stabilization, followed by postoperative chemotherapy. Treatment with albendazole seems to be beneficial both pre- and post-operatively. Recurrence is very frequent after operation hence the need for follow-ups. Treatment outcomes of osseous hydatidosis are satisfactory only in locations where complete and wide excision is possible. In the pelvis and hip, where radical surgery is almost impossible, the results are disappointing.

It is evident that bone hydatid disease must be considered in the differential diagnosis in any cystic lesions that are rarely encountered in body localizations in populations living in endemic regions. With the disease diagnosis challenging, eradication difficult, and increasing recurrent cases, morbidity and mortality high and prognosis poor the best treatment remains an active prevention of the disease in endemic regions.

\section{Acknowledgement}

We acknowledge Mr. A. Wekesa of Egerton Universty, Kenya for technical assistance and critical review of the manuscript.

\section{References}

[1] Arti H, Darani HY. Fibular hydatid cyst. Indian J Orthop. 2007 Jul; 41(3):244-5.

[2] Schantz PM. Echinococcosis. In: Guerrant R, Walker DH, Weller PF, editors.Tropical infectious diseases. Philadelphia, PA: Churchill Livingstone; 1999. 1005-25.

[3] Craig PS, Rogan MT, Allan JC: Detection, screening and community epidemiology of taeniid cestode zoonoses: cystic echinococcosis, alveolar echinococcosis and neurocysticercosis. Adv Parasitol 1996, 38:169-250.

[4] Eckert J, Schantz PM, Gasser RB, Torgerson PR, Bessonov AS, Movsessian SO, Thakur A, Grimm F, Nikogossian MA: Geographic distribution and prevalence of Echinococcus granulosus. In WHO/OIE Manual on Echinococcosis in Humans and Animals: a Public Health Problem of Global Concern: 2001; France. Eckert J, Gemmell MA, Meslin F-X, Pawłowski ZS; 2001:103.

[5] Magambo J, Njoroge E, Zeyhle E. Epidemiology and control of echinococcosis in sub-Saharan Africa. Parasitol Int 2006;55 (Suppl):193-5].

[6] Cooney RM, Flanagan KP, Zehyle E. Review of surgical management of cystic hydatid disease in a resource limited setting: Turkana, Kenya. Eur J Gastroenterol Hepatol. 2004 Nov; 16 (11):1233-6. 
[7] Lozano, R. "Global and regional mortality from 235 causes of death for 20 age groups in 1990 and 2010: a systematic analysis for the Global Burden of Disease Study 2010.". Lancet 380 (9859): 2095-128. doi:10.1016/S01406736(12)61728-0.

[8] World Health Organization. Echinococcosis fact sheet No. 377 March 2014.

[9] Sapkas GS, Stathakopoulos DP, Babis GC, Tsarouchas JK: Hydatid disease of bones and joints. 8 cases followed for 4-16 years. Acta Orthop Scand 1998, 69:89-94.

[10] Arancibia A, Bürgesser MV, Albertini RA, de Diller AL, Villalba CB. Primary hydatid disease of the tibia. case report. Rev Fac Cien Med Univ Nac Cordoba. 2012 Mar; 69(1):51-5.

[11] Kalinova K, Proichev V, Stefanova P, Tokmakova K, Poriazova E: Hydatid bone disease: a case report and review of the literature. Journal of Orthopaedic Surgery 2005, $13: 323-325$.

[12] Merkle EM, Schulte M, Vogel J, Tomczak R, Rieber A, Kern P, Goerich J, Brambs HJ, Sokiranski R: Musculoskeletal involvement in cystic echinococcosis: report of eight cases and review of the literature. Am J Roentgenol 1997, 168:1531-1534.

[13] Tüzün M, Hekimoglu B: CT findings in skeletal cystic echinococcosis. Acta Radiology 2002, 43:533. Morris B, Madiwale C, Gary A, Chavhan G: Case report: Hydatid disease of bone. Australasian Radiology 2002, 46:431].

[14] Chevalier X, Rhamouni A, Bretagne S, Martigny J, LargetPiet B. Hydatid cyst of the subcutaneous tissue without other involvement: MR imaging features. AJR Am J Roentgenol 1994; 163:645.

[15] Abbassioun K, Amirjamshidi A. Diagnosis and management of hydatid cyst of the central nervous system: Part 2: Hydatid cysts of the skull, orbit, and spine. Neuro Quart 2001; 11:106.

[16] Morris BS, Madiwale CV, Garg A, Chavhan GB. Hydatid disease of bone: a mimic of other skeletal pathologies. Australas Radiol 2002; 46:431-4.

[17] Papanikolaou A. Osseous hydatid disease.Trans. R. Soc. Trop. Med. Hyg. 2008. Mar; 102(3): 233-238.

[18] Torricelli P, Martinelli C, Biagini R, Ruggieri P, De Cristofaro R. Radiographic and computed tomographic findings in hydatid disease of bone. Skeletal Radiol 1990; 19:435-9.

[19] Hooper J, McLean I. Hydatid disease of the femur: report of a case. J Bone Joint Surg Am 1977 Oct; 59(7):974-6.

[20] Tuğcu B, Günaldi O, Güneş M, Güler AK, Adilay U, Eseoğlu M, Günal M, Aliş H. Hydatid cysts in uncommon locations in the same patient: simultaneous cardiac and spinal involvement Minim Invasive Neurosurg. 2008 Aug; 51(4):234-6. doi: 10.1055/s-2008-1080904.

[21] Sultana N, Hashim TK, Jan SY, Khan Z, Malik T, Shah W. Primary cervical hydatid cyst: a rare occurrence. Diagn Pathol. 2012 Nov 17; 7:157. doi: 10.1186/1746-1596-7-157.

[22] Yildiz Y, Bayrakci K, Altay M, Saglik Y. The use of polymethylmethacrylate in the management of hydatid disease of bone. J Bone Joint Surg Br 2001 Sep; 83(7):1005-8.

[23] Karadereler S, Orakdógen M, Kiliç K, Ozdogan C. Primary spinal extradural hydatid cyst in a child: Case report and review of the literature. Eur Spine J 2002; 11:500-3.
[24] Herrera A, Martínez AA, Rodríguez J. Spinal hydatidosis.J. Spine (Phila Pa 1976). 2005 Nov 1; 30(21):2439-44.].

[25] Turgut M. Hydatid disease of the spine: A survey study from Turkey. Infection. 1997; 25:221-6.

[26] Turgut AT, Altin L, Topçu S, Kiliçoğlu B, Aliinok T, Kaptanoğlu E, et al. Unusual imaging characteristics of complicated hydatid disease. Eur J Radiol. 2007; 63:84-93.

[27] Secer HI, Anik I, Celik E, Daneyemez MK, Gonul E. Spinal hydatid cyst mimicking arachnoid cyst on magnetic resonance imaging. J Spinal Cord Med. 2008; 31:106-8.

[28] Ndondo AP, Fieggen G, Wilmshurst JM. Hydatid disease of the spine in South African children. J Child Neurol. 2003; $18: 343-6$

[29] Yilmaz N, Ozgocmen S, Kocakoc E, Kiris A. Primary hydatid disease of sacrum affecting the sacroiliac joint: A case report. Spine (Phila Pa 1976) 2004; 29:E88-90.

[30] Ergin A, Toker T, Yanarates O, Kurt E, Guzeldemir ME. A typical low-back pain caused by an atypical etiology. Reg Anesth Pain Med. 2007; 32:89-92.

[31] Layadi F, Boubrik M, Ait El Qadi A, Ait Benali S. Primary sacral epidural hydatid cyst: A case report. J Radiol. 2005; 86:1040-2.].

[32] Song X, Liu D, Wen H. Diagnostic pitfalls of spinal echinococcosis. J Spinal Disord Tech.2007;20:180-5.

[33] Işslekel S, Erşahin Y, Zileli M, Oktar N, Oner K, Ovül I, et al. Spinal hydatid disease. Spinal Cord.1998;36:166-70.

[34] Fiennes AG, Thomas DG. Combined medical and surgical treatment of spinal hydatid disease: A case report. J Neurol Neurosurg Psychiatry. 1982; 45:927-30.

[35] Patel D, Shukla D. Back bugged: A case of sacral hydatid cyst. J Neurosci Rural Pract. 2010; 1:43-5.

[36] Shukla S, Trivedi A, Singh K, Sharma V. Primary lumbosacral intradural hydatid cyst in a child. J Neurosci Rural Pract. 2010, $1: 109-111$.

[37] Sharma NK, Chitkara N, Bakshi N, Gupta P. Primary spinal extradural hydatid cyst. Neurol India.2003; 51:89-90.

[38] Berk C, Ciftci E, Erdogan A. MRI in primary intraspinal extradural hydatid disease: Case report.Neuroradiology. 1998; $40: 390-2$.

[39] Pamir MN, Akalan N, Ozgen T, Erbengi A. Spinal hydatid cysts. Surg Neurol. 1984; 21:53-7.

[40] Joshi N, Hernandez-Martinez A, Seijas-Vazquez R. Primary sacral hydatid cyst: A case report. Acta Orthop Belg. 2007; 73:674-7.

[41] Govender TS, Aslam M, Parbhoo A, Corr P. Hydatid disease of the spine: A long-term followup after surgical treatment. Clin Orthop Relat Res. 2000; 378:143-7.

[42] Dogra PN, Nabi G. Sacral hydatid cysts: An uncommon cause of neurogenic bladder. Urol Int.2000; 65:214-5.]

[43] Scarlata F, Giordano S, Saporito L, Marasa L, Li Pani G, Odierna A, Scaglione V, Di Carlo P, Romano A. Cystic hydatidosis: a rare case of spine localization. Infez Med. 2011 Mar; 19(1):39-41]. 
[44] Senol MG, Tekeli H, Kendirli MT, Kaya S, Turhan V, Sonmez G, Saracoglu M. Intramedullary hydatid cyst of the cervical spine. Indian J Med Microbiol. 2014 Jan-Mar; 32(1):101.

[45] Bozbuga M, Celikoglu E, Boran BO. Hydatid cyst of the craniocervical junction: case report. Neurosurgery. $2005 \mathrm{Jul}$; 57(1):E193; discussion E193.

[46] Katilmiş H, Oztürkcan S, Ozdemir I, Adadan Güvenç I, Ozturan S. Primary hydatid cyst of the neck.Am J Otolaryngol. 2007 May-Jun; 28(3):205-7.

[47] Güneçs M, Akdemir H, Tuğcu B, Günaldi O, Gümüçs E, Akpinar A. Multiple intradural spinal hydatid disease: a case report and review of literature. Spine (Phila Pa 1976). 2009 Apr 20; 34(9):E346-50. doi: 10.1097/BRS.0b013e3181a01b0f.]

[48] Sasani M, Ozer AF. Spontaneous drainage of an asymptomatic recurrent hydatid cyst of the sacrum. Spine (Phila Pa 1976). 2009 Apr 1; 34(7):E269-71. doi: 10.1097/BRS.0b013e3181959ed7.

[49] Tabak O, Yilmaz M, Oz B, Ozaras R, Erdincler P, Mert A, Ozturk R, Tabak F. A vertebral hydatid cyst infection mimicking tuberculous spondylodiscitis. J Infect Chemother. 2007 Jun; 13(3):180-2.

[50] Lath R, Ratnam BG, Ranjan A. Diagnosis and treatment of multiple hydatid cysts at the craniovertebral junction. Case report. J Neurosurg Spine. 2007 Feb; 6(2):174-7.

[51] Kotil K, Tatar Z, Bilge T. Spinal hydatidosis accompanied by a secondary infection. Case report. J Neurosurg Spine. 2007 Jun; 6(6):585-90.

[52] Erayman I, Kalkan E, Erdi F, Kerimoglu Ü, Esen H. Primary spinal hydatid cyst in a patient with acquired immunodeficiency syndrome. Eur Spine J. 2011 Jul;20 Suppl 2:S235-8. doi: 10.1007/s00586-010-1614-4.

[53] Ashraf A, Kirmani AR, Bhat AR, Sarmast AH. A rare case of recurrent primary spinal echinococcosis. Asian J Neurosurg. 2013 Oct;8(4):206-8. doi: 10.4103/1793-5482.125679.

[54] Ozkan H, Dogramaci Y, Kose O, Esen E, Erdem H, Komurcu M. Primary hydatid disease of the humerus. Ann Acad Med Singapore. 2008 May; 37(5):440-1.

[55] Jellali MA, Zrig M, Zrig A, Mnif H, Hmida B, Abid A, Golli M. Pathological humeral fracture revealing bone hydatic cyst. Med Mal Infect. 2011 Mar; 41(3):164-6.]

[56] Ouadnouni Y, Bouchikh M, Achir A, Smahi M, Msougar Y, Lakranbi M, Alaziz AS, Benosman A. Hydatid disease of the ribs. Rev Mal Respir. 2011 Mar; 28(3):306-11. doi: 10.1016/j.rmr.2011.02.003.

[57] Demir HA, Demir S, Emir S, Kacar A, Tiryaki T. Primary hydatid cyst of the rib mimicking chest wall tumor: a case report. J Pediatr Surg. 2010 Nov; 45(11):2247-9. doi: 10.1016/j.jpedsurg.2010.06.041.

[58] Alimohamadi S, Dehghan A, Neghab N. Primary bilateral intrapelvic hydatid cyst presenting with adnexal cystic mass: a case report. Acta Med Iran. 2011; 49 (10):694-6.

[59] Siwach R, Singh R, Kadian VK, Singh Z, Jain M, Madan H, Singh S. Extensive hydatidosis of the femur and pelvis with pathological fracture: a case report.Int J Infect Dis. 2009 Nov; 13(6):e480-2.
[60] Ait Benkaddour Y, Mansouri MZ, Rabbani K, Jalal H, Aboulfalh A, Abbassi H. Primary pelvic hydatid cyst an unusual cause of cystic adnexal image (mass). Afr J Reprod Health. 2011 Jun; 15(2):165-8. Erratum in: Afr J Reprod Health. 2013 Mar; 17(1):174. Afr J Reprod Health. 2013 Mar; 17(1):174.

[61] de Lavaissiere M, Voronca C, Ranz I, Pirame M, Hounieu H, Carreiro M. Pelvic hydatid cyst: differential diagnosis with a bacterial abscess with cutaneous fistula. Bull Soc Pathol Exot. 2012 Oct; 105(4):256-8. doi: 10.1007/s13149-011-0196-7.

[62] Ciurea AV, Fountas KN, Coman TC, Machinis TG, Kapsalaki EZ, Fezoulidis NI, Robinson JS. Long-term surgical outcome in patients with intracranial hydatid cyst. Acta Neurochir (Wien). 2006 Apr; 148(4):421-6.

[63] Limaiem F, Bellil S, Bellil K, Chelly I, Mekni A, Kallel J, Haouet S, Zitouna M, Kchir N. Hydatid cyst of the cranial vault. J Infect Dev Ctries. 2009 Dec 15; 3(10):807-10.

[64] Papanikolaou A, Antoniou N, Pavlakis D, Garas G. Hydatid disease of the tarsal bones. A case report. J Foot Ankle Surg. 2005 Sep-Oct; 44(5):396-400.

[65] Mondal SK, Sengupta SG. Hydatid cyst of radial bone. JNMA J Nepal Med Assoc. 2009 Oct-Dec; 48(176):321-3.

[66] Massè A, Parola PG, Brach del Prever EM, Gallinaro P. Hydatidosis of the pelvis: a case report with a 25-year followup. Arch Orthop Trauma Surg. 2004 Apr; 124(3):203-5. Epub $2004 \mathrm{Feb} 10$.

[67] Bulut M, Tosun HB, Simsek BC, Karakurt L.J Primary hydatid cyst of the scaphoid: case report. Hand Surg Am. 2012 May; 37(5):1051-3. doi: 10.1016/j.jhsa.2012.02.024.

[68] Zahed HM, Mizanur RM, Mohammad BS. Cranial hydatid abscess.Trop Doct. 2010 Oct;40(4):255-6. doi: $10.1258 / \mathrm{td} .2010 .090454$.

[69] Lone YA, Mumtaz I, Mushtaq E, Sarmast AH, Kachroo MY. Recurrent primary hydatid disease of the tibia. West Indian Med J. 2013 Dec; 62(9):866-8. doi: 10.7727/wimj.2012.185.

[70] Banerjee S, Sabui KK, Mondal J, Nath C, Pal DK. Composite treatment for primary long-bone hydatidosis. Orthopedics. 2012 Dec; 35(12):e1826-31. doi: 10.3928/0147744720121120-34.

[71] Martin J, Marco V, Zidan A, Marco C. Hydatid disease of the soft tissues of the lower limb: findings in three cases. Skeletal Radiol 1993 Oct; 22(7):511-4.

[72] Turgut AT, Turgut M. Intradural extramedullary primary hydatid cyst of the spine in a child: A very rare presentation. Eur Spine J. 2009; 18:1234-5.

[73] Song XH, Ding LW, Wen H. Bone hydatid disease. Postgrad Med J. 2007; 83:536-42.

[74] Doganay S, Kantarci M. Role of conventional and diffusionweighted magnetic resonance imaging of spinal treatment protocol for hydatid disease. J Spinal Cord Med. 2009; 32:574-7.

[75] Ozdemir HM, Ogun TC, Tasbas B. A lasting solution is hard to achieve in primary hydatid disease of the spine: Long-term results and an overview. Spine (Phila Pa 1976) 2004; 29:9327. 
[76] Garcia-Vicuna R, Carvajal I, Ortiz-Garcia A, LopezRobledillo JC, Laffon A, Sabando P. Primary solitary Echinococcosis in cervical spine: Postsurgical successful outcome after long-term albendazole treatment. Spine (Phila $\mathrm{Pa}$ 1976) 2000; 25:520-3.

[77] Khazim RM. Spinal hydatid disease. South Med J. 2006; 99:114.

[78] Pamir MN, Ozduman K, Elmaci I. Spinal hydatid disease. Spinal Cord. 2002; 40:153-60.

[79] Ouma JR. Echinococcosis-a rare spinal disorder. (682).S Afr Med J. 2006; 96:680.
[80] Fares Y, Khazim R, El Zaatari MM, Haddad GF, Barnes PR. Spinal hydatid disease and its neurological complications. Scand J Infect Dis. 2003; 35:394-6.

[81] Chaudhary K, Bapat M, Badve S. Paraplegia due to recurrent multiple hydatid cyst of the spine: A case report. Indian J Orthop. 2008; 42:222-4.

[82] Turtas S, Viale ES, Pau A. Long-term results of surgery for hydatid disease of the spine. Surg Neurol.1980; 13:468-70

[83] Schnepper GD, Johnson WD. Recurrent spinal hydatidosis in North America: Case report and review of the literature. Neurosurg Focus. 2004; 17:E8.]. 